\title{
Magnetic Hyperthermia Using Self-Controlled Heating Elements Consisting of Fe-Al Milling Alloy Induces Cancer Cell Apoptosis while Preserving Skeletal Muscle
}

\author{
Isao Kawahara ${ }^{a}$ b Kei Goto $^{a}$ Kenji Kodamac Yi Luo $^{a}$ Rina Fujiwara-Tani ${ }^{a}$ Takuya Moria, b \\ Yoshihiro Miyagawa ${ }^{a}$ Hirokazu Tanakad Hiroyuki Kodamad Nobuyoshi Hosoito ${ }^{\mathrm{e}}$ \\ Yukinori Taniguchic Hiroki Kuniyasu ${ }^{a}$ \\ a Department of Molecular Pathology, Nara Medical University, Kashihara, Japan; ' bivision of Rehabilitation, Hanna \\ Central Hospital, Ikoma, Japan; ' Graduate School of Materials Science, Nara Institute of Science and Technology,

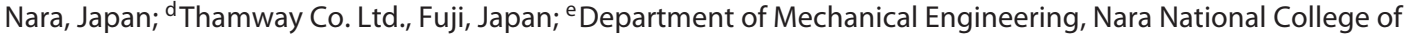 \\ Technology, Ikoma, Japan
}

\section{Keywords}

Autophagy · Sarcopenia $\cdot$ Hyperthermia

\section{Abstract}

Necrosis-inducing anticancer drugs enhance high-mobility group box 1 (HMGB1) release during cell necrosis, and HMGB1-induced autophagy in skeletal muscle induces muscle atrophy. We evaluated the efficacy of magnetic hyperthermia therapy (MHT) using a low-energy magnetic field and self-controlled heating elements in tumor treatment. MHT-induced apoptosis by heating mouse subcutaneous tumors at $43^{\circ} \mathrm{C}$ using a heat-controlling iron-aluminum (FeAl) milling alloy. In contrast, MHT using Fe line-induced necrosis by heating to approximately $100^{\circ} \mathrm{C}$. Furthermore, $\mathrm{MHT}$ with Fe-Al milling alloy reduced stemness. In hyperthermia using age line or Fe-Al milling alloy, both of them provided histological degeneration in skeletal muscle; however, qualitative differences were observed. MHT using Fe-line induced pronounced autophagy, decrease of myosin heavy chain content, and increase in serum HMGB1. In contrast, MHT using Fe-Al milling alloy induced heat shock protein 90 but no autophagy and decreased serum HMGB1. Therefore, MHT using Fe-Al milling alloy might be a good method for local treatment of tumors to reduce skeletal muscle atrophy.

(c) 2019 S. Karger AG, Basel

\section{Introduction}

Atrophy of skeletal muscle is a hallmark of cancer progression [1]. Cancer sarcopenia is thought to be caused by negative remodeling of skeletal muscle by cancer-derived inflammatory cytokines such as in cachexia $[2,3]$. It is generally accompanied by reduced response to therapy that worsens prognosis, restricts patient activity, and lowers the overall quality of life $[3,4]$. Prevention or treatment of muscle atrophy improves patient prognosis [3]. Thus, it is vital that sarcopenia be diagnosed early and treated in cancer patients undergoing therapy.

I.K. and K.G. contributed equally to this work.

\section{KARGER}

(C) 2019 S. Karger AG, Basel

E-Mail karger@karger.com

www.karger.com/pat
Hiroki Kuniyasu

Department of Molecular Pathology

Nara Medical University

840 Shijo-cho, Kashihara, Nara 634-8521 (Japan)

E-Mail cooninh@zb4.so-net.ne.jp 
We have previously reported that cancer cells secrete high-mobility group box 1 (HMGB1) to activate receptors for advanced glycation end products and Toll-like receptor- 4 and to induce autophagy in skeletal muscle [5]. Glutamine generated from protein degradation by HMGB1-induced autophagy is released into the bloodstream by skeletal muscle cells. This glutamine is taken up by cancer cells and utilized in lactate production [5].

HMGB1 is released by necrotic cells [6]. Chemotherapeutic drugs that induce necrosis elevate the serum concentration of HMGB1, which, in turn, reactivates residual cancer cells and worsens sarcopenia [7]. In contrast, apoptosis inducers do not induce the release of HMGB1 [7]. Chemotherapeutic regimens that largely use necrosis inducers may pose a risk for sarcopenia.

Hyperthermia injures cancer cells selectively by utilizing their higher susceptibility to elevated temperature $\left(43^{\circ} \mathrm{C}\right)$ compared to normal cells [8]. Heat shock evokes proteasome degradation and subsequent protein aggregation and macroautophagy [9]. Furthermore, heatshock-induced endoplasmic stress also initiates apoptosis [9].

Hyperthermia in cancer cells is induced using physical energy in the form of applied electromagnetic field, ultrasonic pressure wave, and circulation of preheated blood [8]. Heat induction by magnetic fields could either be through applying very strong magnetic fields that generate heat energy in the tissue or by a low-energy magnetic field that uses heating elements such as metal pieces, the latter being a lower-cost and more manageable option. We examined a self-controlled heating element that uses low-energy magnetic field for application of low-energy magnetic hyperthermia (MHT) to tumor treatment. To prepare the self-controlled heating element, we employed the method of mechanical milling from iron and aluminum powder [10]. Magnetic hysteresis of the milling alloy shows higher coercivity and slope of magnetization curve than those of unmilled metal powder [10]. By using ironaluminum ( $\mathrm{Fe}-\mathrm{Al})$ milling alloy, we tested the heating and temperature stability in the subcutaneous tumor of the mouse model.

\section{Materials and Methods}

\section{Cells}

The CT26 mouse colon cancer cell line was a kind gift from Professor I. J. Fidler (MD Anderson Cancer Center, Houston, TX, USA). Cells were cultured in Dulbecco's modified Eagle's medium (Wako Pure Chemical, Osaka, Japan) supplemented with 10\% fetal bovine serum (Sigma Chemical Co., St. Louis, MO, USA).
Reagent

Doxorubicin (DXR), trichostatin A (TSA; Sigma), and HMGB1 ( $R \& D$ Systems, Minneapolis, MN, USA) were treated. In in vitro experiments, DXR (10 $\mu \mathrm{g} / \mathrm{mouse})$, or TSA (1.2 mg/mouse), were administrated by intraperitoneal injection. HMGB1 (10-100 $\mu \mathrm{g} /$ mouse) was administrated by intraperitoneal injection in mice.

\section{Animals}

Four-week-old male BALB/c mice were purchased from SLC Japan (Shizuoka, Japan). The animals were maintained in accordance with the institutional guidelines approved by the Committee for Animal Experimentation of Nara Medical University, following current regulations and standards of the Japanese Ministry of Health, Labor, and Welfare (Approval Number). To establish a subcutaneous tumor model, CT26 cancer cells $\left(1 \times 10^{7}\right)$ were inoculated into the scapular subcutaneous tissue of BALB/c mice (4 mice in each group). When tumors grew to $1 \mathrm{~cm}$ in diameter after 2 weeks after the inoculation, mice were treated with PBS, DXR (10 $\mu \mathrm{g} /$ mouse), TSA (1.2 mg/mouse) by intraperitoneal injection (total volume was $100 \mu \mathrm{L}$ ), or MHT by Fe line or by Fe-Al milling alloy bead. Mice were observed for 4 weeks following inoculation. We used raw chicken muscle purchased edible chicken meat on a food commercial basis for evaluating heat effect to the tissue. Chicken muscle tissue sections $(2 \times 2 \times 2 \mathrm{~cm})$ were used to examine the effect of hyperthermia on histological alteration.

\section{Heating Element and Magnetic Generator}

Two types of heating elements: (1) a line (1 mm in diameter) or a bead $(0.8 \mathrm{~mm}$ in diameter), which consisted of aluminum-iron milling alloy beads, and (2) an iron line (Fe line, $0.8 \mathrm{~mm}$ in diameter) were prepared. The mixture of aluminum and iron was treated by ball milling for $16 \mathrm{~h}$ to produce the alloy at a 50:50 final composition. The alloy shows more pronounced stable coercivity (25 Oe) for higher magnetic thermogenesis compared to the melting alloy with the same composition $[11,12]$.

Magnetic field was applied on the animal by a copper air-core coil (magnetic field generation: 60 gauss, inside diameter: $8 \mathrm{~cm}$, outside diameter: $9.6 \mathrm{~cm}$, scroll number: 10 , scroll length: $13 \mathrm{~cm}$, coil wire diameter: $6 \mathrm{~mm}$; Thamway Co. Ltd., Fuji, Japan) by placing the animal inside the coil. The coil was activated by an alternating current up to $800 \mathrm{~W}$, which generated a magnetic field of 100 Oe and $225 \mathrm{kHz}$ using a power generator controlled by an amplifier (Thamway) [11, 12]. The core temperature of the animal was measured by a digital thermometer with a sensor wire (Tasco Japan Co., Osaka, Japan) inserted in the center of the tumor as expected from its appearance. Following treatment, the mice were anesthetized with intraperitoneal pentobarbital injection (Kyoritsu Seiyaku, Tokyo, Japan, $20 \mathrm{mg} / \mathrm{kg}$ ) and inhalation of 3\% isoflurane (Wako) inside the coil.

\section{Immunohistochemistry}

Consecutive $4 \mu \mathrm{m}$ sections were immunohistochemically stained using the immunoperoxidase technique, as described previously [13]. Antibody against mouse nucleostemin (NS; SantaCruz Biotechnology, Inc., Dallas, TX, USA), a stem cell marker, and ubiqutin (Cytoskeleton Inc., Denver, CO, USA) were used at $0.5 \mu \mathrm{g} / \mathrm{mL}$. Color development was achieved using 3-3'-diaminobenzidine (DAKO, Carpineria, CA, USA). Specimens were counterstained with Meyer's hematoxylin stain (Sigma) to visualize the nuclei. After immunostaining, the number of positively stained 
nuclei was counted by microscopy. The percent frequency of NSpositive cells was calculated from the ratio of positive nuclei to 500 examined nuclei.

\section{TdT-Mediated dUTP Nick End Labeling Assay}

Mediated dUTP nick end labeling assay using the In Situ Cell Death Detection Kit (Roche Diagnostics, Indianapolis, IN, USA). The percent frequency of mediated dUTP nick end labeling-positive cells was calculated from the ratio of positive nuclei to 500 examined nuclei [7].

\section{Necrosis Measurement}

Tissue image of hematoxylin and eosin staining was captured into computer and necrotic area was marked and calculated by NIH image (National Institutes of Health, Bethesda, MD, USA) [14].

\section{Immunoblot Analysis}

Whole-cell lysates were prepared as described previously [15]. Twenty-microgram lysates were subjected to immunoblot analysis in $12.5 \%$ sodium dodecyl sulfate-polyacrylamide gels followed by electrotransfer onto nitrocellulose filters. The filters were incubated with primary antibodies and then with peroxidase-conjugated IgG antibodies (MBL, Nagoya, Japan). A tubulin antibody was used to assess the levels of protein loaded per lane (Oncogene Research Products, Cambridge, MA, USA). The immune complex was visualized by CSA system (DAKO, Carpinteria, CA, USA). Antibodies for heat shock protein 90 (SHP90, Abnova), phosphorylated mTOR (pSer2448, Assay Biotechnology, Sunnyvale, CA, USA), Beclin 1 (Santa-Cruz Biotechnology, Santa Cruz, CA, USA), and LC3 (Cosmo Bio, Tokyo, Japan) were used as primary antibodies.

Enzyme-Linked Immunosorbent Assay and Enzyme Assay

Mouse blood was collected from the heart. The blood was rapidly centrifuged by $500 \mathrm{~g}, 4 \mathrm{~min}$ at $4^{\circ} \mathrm{C}$ and the supernatant was used as serum. The serum or whole lysates of tissues were subjected to enzyme-linked immunosorbent assay (ELISA) and enzyme assay. HMGB1, myosin heavy chain (myosin HC), and lactate dehydrogenase were measured by each specific ELISA kit (Shinotest, Tokyo, Japan, Uscn Life Science, LifeSpan BioSciences Inc., Seattle WA, USA, and Uhan, China, respectively). Glutamine was measured by L-glutamine assay kit (DAKO). ELISA or enzyme assay was performed according to provider's instructions. The experiment was repeated 3 times.

\section{Statistical Analysis}

Results were analyzed using the unpaired Student-t test or ordinary ANOVA with Bonferroni correction for multiple comparisons by using InStat software (GraphPad, Los Angeles, CA, USA). Differences between means were considered statistically significant when the two-sided $p$ value $<0.05$.

\section{Results}

\section{Effect of Anticancer Agent on Tumor and Skeletal} Muscle

First, the effect of DXR and TSA on tumor cells was examined in CT26 subcutaneous tumors (Fig. 1). In Fig- ure 1a and b, DXR increased serum lactate dehydrogenase, a necrosis marker, but not apoptosis. In contrast, TSA induced mainly apoptosis, but not necrosis. Next, the effects of the anticancer agents on skeletal muscle weight (Fig. 1c) and muscle maturity (Fig. 1d; myosin HC) were determined. Tumor-burdened animals showed a decrease of muscle weight and myosin $\mathrm{HC}$ content. DXR-treated mice, in particular, showed most pronounced loss of muscle weight and myosin HC content. In Figure 1e, the skeletal muscle in DXR-treated mice burden with subcutaneous tumors of CT2 6 cells was atrophic in hematoxylin and eosin staining; decrease of muscle fiber volume, and eosin staining. In contrast, the muscle in TSA-treated mice showed no significant alteration in comparison with the muscle in PBS-treated mice. Moreover, the muscle in DXR-treated mice showed increase of immunoreactivity for ubiquitin in a diffuse manner. In contrast, the muscle treated with TSA-treated mice showed no increase of ubiquitin.

\section{Effect of MHT on Tumor}

We established a system of MHT using Fe-Al milling alloy heating element (Fig. 2a). A spherical element ( $2 \mathrm{~mm}$ in diameter) consisting of Fe-Al milling alloy was inserted into the tumor using an $18 \mathrm{G}$ needle. The electromagnetic coil was activated by a power generator (700 W alternating current) controlled by an amplifier, made by Thamway Co. Ltd. The temperature in the center of the tumor was maintained at $43^{\circ} \mathrm{C}$ (Fig. 2b, c). The alloy bead was embedded in the tumor and an area of $1 \mathrm{~cm}$ in diameter (arrow) was degradated around the bead hole (Fig. 2d).

The mean temperature was approximately $43^{\circ} \mathrm{C}$ in the tumor heated by the alloy bead, whereas the tumor temperature heated with the Fe line reached around $90^{\circ} \mathrm{C}$ (Fig. 2e). Apoptotic cell death was induced to more pronounced levels in tumors treated by the alloy bead than those in tumors heated by the Fe line (Fig. 2f). The area of nonapoptotic cell death was more pronounced in tumors treated by the Fe line than those treated by the alloy bead (Fig. 2g). NS-expressing cells decreased in number after the alloy bead treatment compared to that after the Fe line treatment (Fig. 2h).

\section{Effect of MHT on Tumor-Adjacent Skeletal Muscle}

To confirm the effect of MHT on the skeletal muscle adjacent to the heated tumor, we evaluated the direct effect of heating by MHT on chicken muscle. Chicken muscle was heated by Fe-Al milling alloy line for 0,1 , and 5 min. Muscle tissue sections exhibited varying degrees of 
Fig. 1. Necrosis-inducer induces skeletal muscle atrophy in cancer-burden mice. $\mathrm{BALB} / \mathrm{c}$ mice ( 4 weeks old, male) with subcutaneous inoculation with CT26 cells (4 mice in each group). When tumors grew to $1 \mathrm{~cm}$ in diameter after 2 weeks after the inoculation, mice were treated with PBS, DXR (10 $\mu \mathrm{g} / \mathrm{mouse})$, or TSA (1.2 mg/ mouse) by intraperitoneal injection (total volume was $100 \mu \mathrm{L}$ ). a, b Concentration of LDH in the serum measured by ELISA (a) and apoptosis assessed by mediated dUTP nick end labeling assay (b) of CT26 cancer cells. c, d Wet weight of femoral quadriceps muscle (c) and myosin HC contents measured by ELISA (d). Error bar, SD. e Microphotographs of the femoral quadriceps muscle of the BALB/c mice with subcutaneous tumors of CT26 cells, which were treated with PBS, DXR or TSA. Upper row, $\mathrm{H} \& \mathrm{E}$; lower row, immunostaining with anti-ubiquitin antibody. Bar, $200 \mu \mathrm{m}$. LDH, lactate dehydrogenase; DXR, doxorubicin; TSA, trichostatin A; H\&E, hematoxylin and eosin.

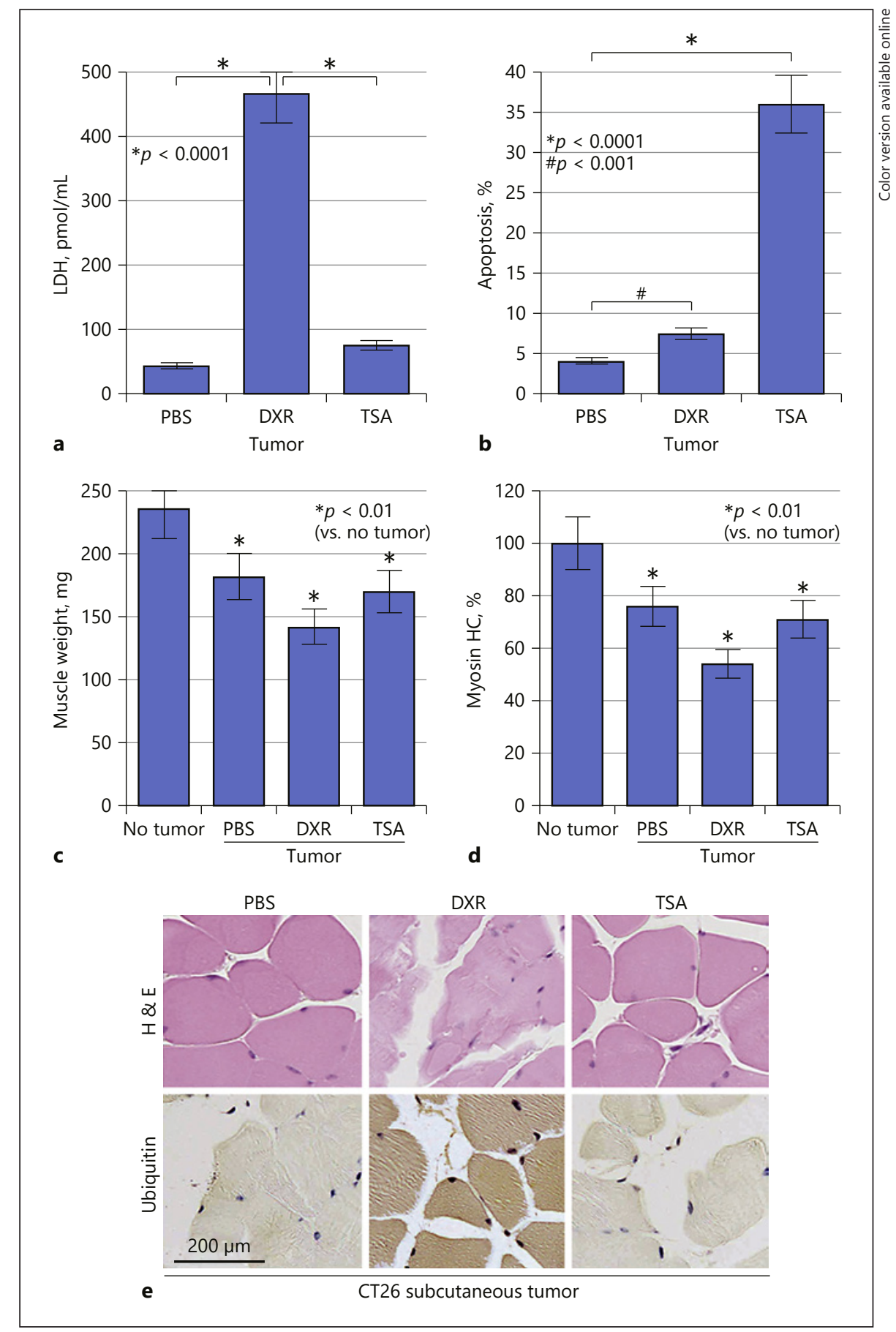

degeneration under the microscope categorized as normal, mild, and marked levels (Fig. 3a). Further histological examination revealed that myosinHC content was decreased (Fig. 3b) and apoptosis was increased (Fig. 3c) under hyperthermia.

MHT Using Self-Controlled Heating Elements in Cancer
We next examined the perispinal muscles adjacent to the subcutaneous tumors heated by the alloy bead or Fe line (Fig. 3d). The number of apoptotic cells was not significantly different between the 2 groups (Fig. 3e). However, the muscle adjacent to the tumor treated by the alloy bead showed higher myosin HC than those by the Feline (Fig. 3f). 
Fig. 2. MHT system with Fe-Al milling alloy beads. a Scheme of the animal experimental model for MHT. A target mouse is located in the coil. b Time course of the core temperature of the tumor with one inserted bead. The magnetic field was generated at $700 \mathrm{~W}$. c Cut surface of the excised tumor. The inserted bead (arrow). Bar, 3 mm. d H\&E staining of the tumor. Black dots, the bead hole; yellow dots, degenerated area; arrow, diameter of degeneration $(1.2 \mathrm{~cm})$. Bar, $3 \mathrm{~mm}$. e-h Mean core temperature during heating. The insertion site of the temperature sensor was indicated in panels $\mathbf{c}$ and $\mathbf{d}$ by X mark (e), apoptotic cell percentage assessed by mediated dUTP nick end labeling assay (f), proportion of the area of nonapoptotic cell death to the area of degradation of skeletal muscle measured by image analysis (g), and the nucleostamine (NS)-positive cell percentage (h) was compared between tumors treated with Fe-Al milling alloy bead and Fe line. Error bar, SD. Al-Fe, aluminum-iron; Fe$\mathrm{Al}$, iron-aluminum; NS, nucleostemin.

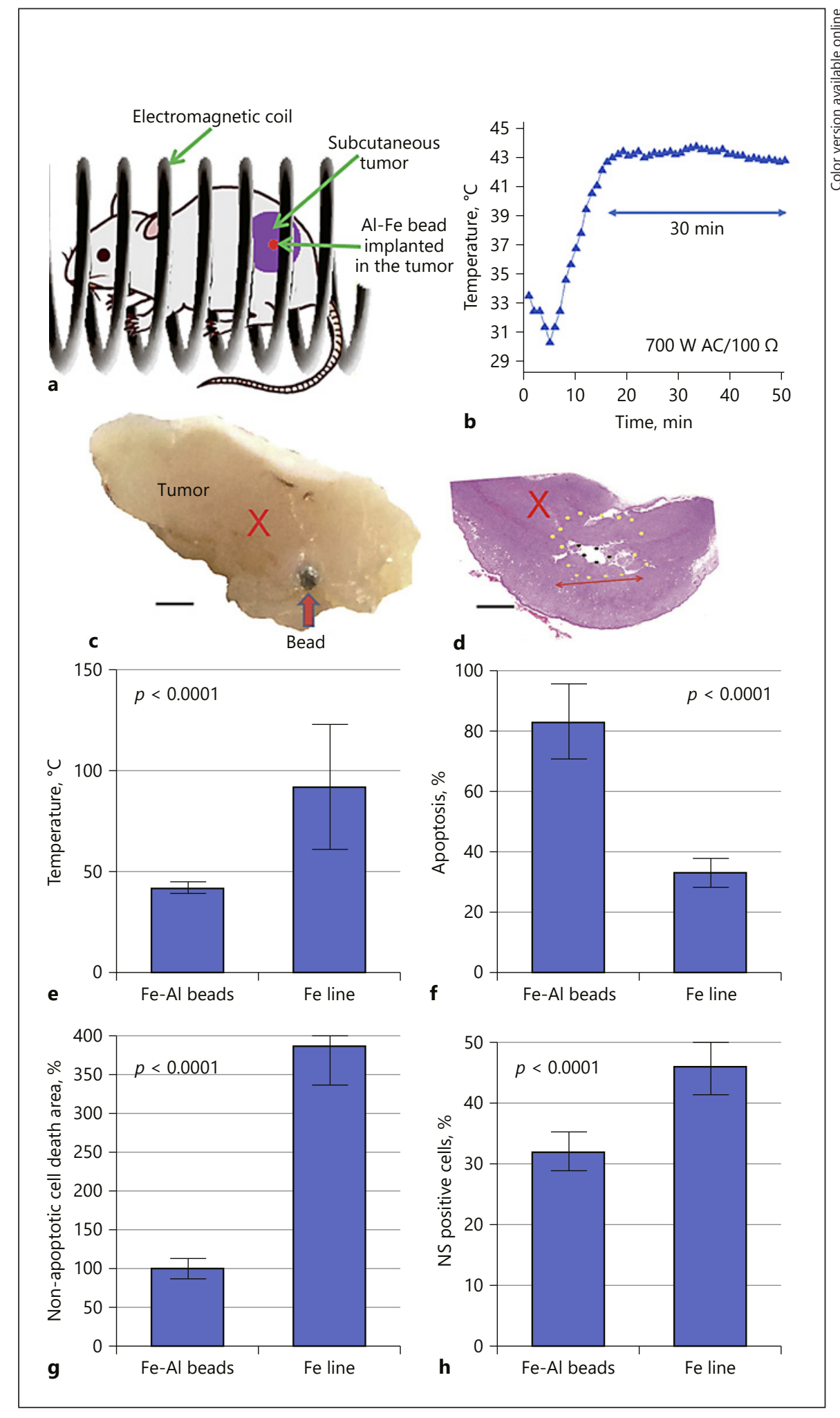


Fig. 3. Influence of MHT on skeletal muscle. a-c Raw chicken muscle nuggets were subjected to MHT using Fe-Al milling alloy line. a H\&E staining of the muscles heated for 0,1 , or $5 \mathrm{~min}$, which yielded "None," "Mild," and "Marked" degradation, respectively. b, c Myosin HC content (b) and apoptosis (c) were compared among the muscle tissue sections with "None," "Mild," and "Marked" degradation. d-f Examination of perispinal muscles neighboring the subcutaneous tumors in $\mathrm{BALB} / \mathrm{c}$ mice, which were heated by Fe-Al bead or Fe line as shown in Figure 2. d H\&E staining of the perispinal muscle. Bar, $2 \mathrm{~mm}$. myosin $\mathrm{HC}$ content (e) and apoptosis (f) were compared between tumors treated with $\mathrm{Fe}-\mathrm{Al}$ milling alloy bead and Fe line. Error bar, $\mathrm{SD}$. myosin HC, myosin heavy chain; Fe$\mathrm{Al}$, iron-aluminum.

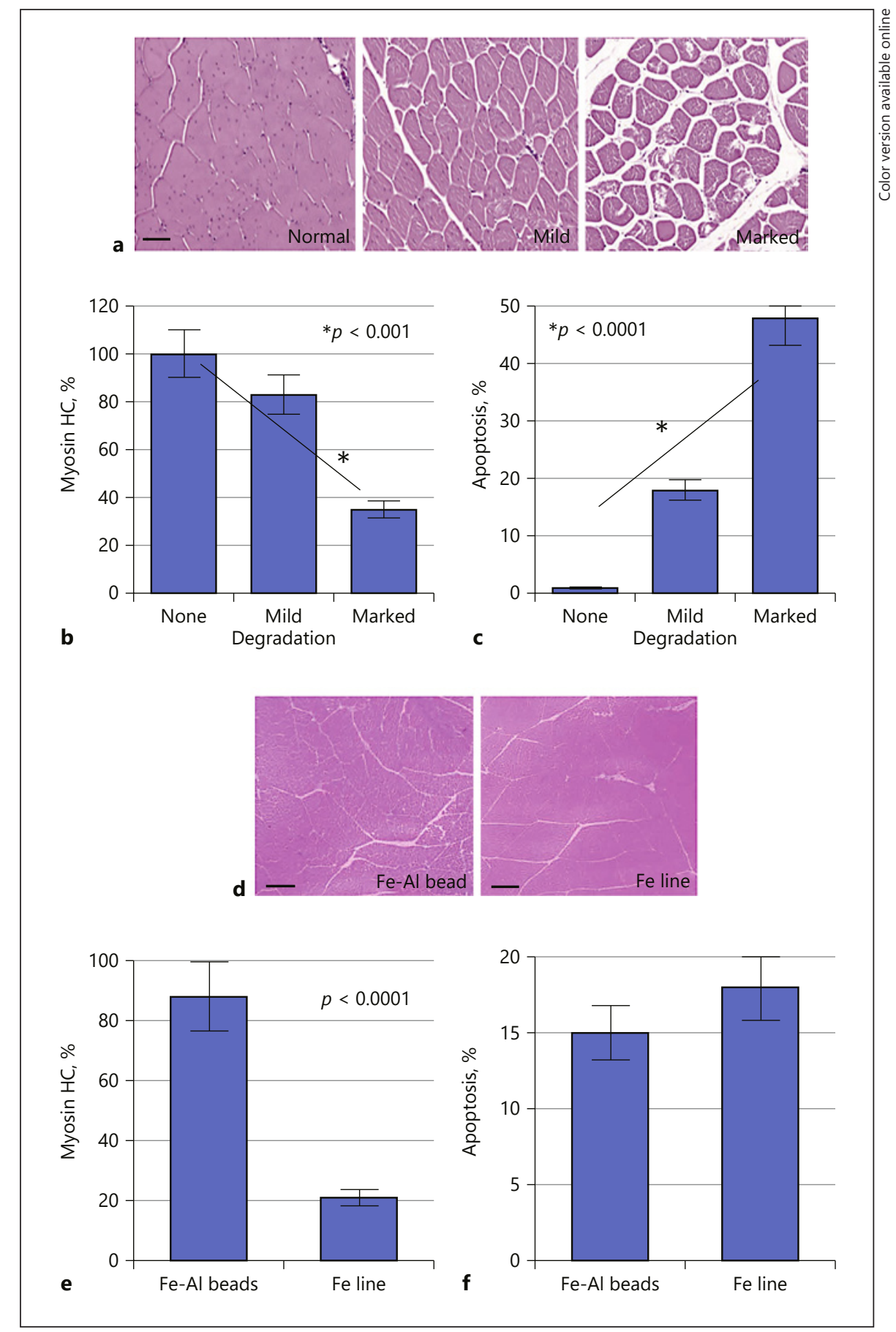

\section{Effect of MHT on the Cancer-Muscle Relationship}

We evaluated the HMGB1 signal in the muscle tissue heated by the alloy beads or Fe line (Fig. 4). In Figure 4a, serum HMGB1 levels were compared among cell death inducer and hyperthermia (Fe-Al bead or Fe line)-treated groups. DXR but not TSA showed high levels of HMGB1. Heating by Fe line yielded high serum HMGB1 levels similar to those by the necrosis inducer, whereas alloybased heating yielded low serum HMGB1 levels similar to those by the apoptosis-inducer.

Effect of HMGB1 on muscle atrophy was examined by the administration of HMGB1 to mice without tumor (Fig. 4b). The muscle weight was correlated inversely to the dosage of HMGB1. The autophagy-related alteration 
Fig. 4. Effect of MHT on autophagy in skeletal muscles in cancer-burden mice. $\mathrm{BALB} / \mathrm{c}$ mice (4 weeks old, male) with subcutaneous inoculation with CT26 cells (4 mice in each group). When tumors grew to $1 \mathrm{~cm}$ in diameter after 2 weeks after the inoculation, mice were treated with PBS, DXR (10 $\mu \mathrm{g} / \mathrm{mouse})$, TSA (1.2 mg/mouse) by intraperitoneal injection (total volume was $100 \mu \mathrm{L}$ ) or MHT by Fe line or by $\mathrm{Fe}-\mathrm{Al}$ milling alloy bead. a Serum HMGB1 concentrations were examined in mice treated with DXR (necrosis-inducer), TSA (apoloy bead or Fe line by ELISA. b Wet weight of the femoral quadriceps muscles of $\mathrm{BALB} / \mathrm{c}$ mice treated with HMGB1 i.p. by one shot. c Expression of autophagy-associated proteins in the muscle of mice treated with MHT was examined by western blot analysis. d Serum glutamine concentrations were examined in mice treated with DXR, TSA, and MHT by an EA kit. Error bar, SD. HMGB1, high-mobility group box 1; DXR, doxorubicin; TSA, trichostatin $\mathrm{A} ; \mathrm{Fe}-\mathrm{Al}$, iron-aluminum. ptosis-inducer), MHT by Fe-Al milling al-
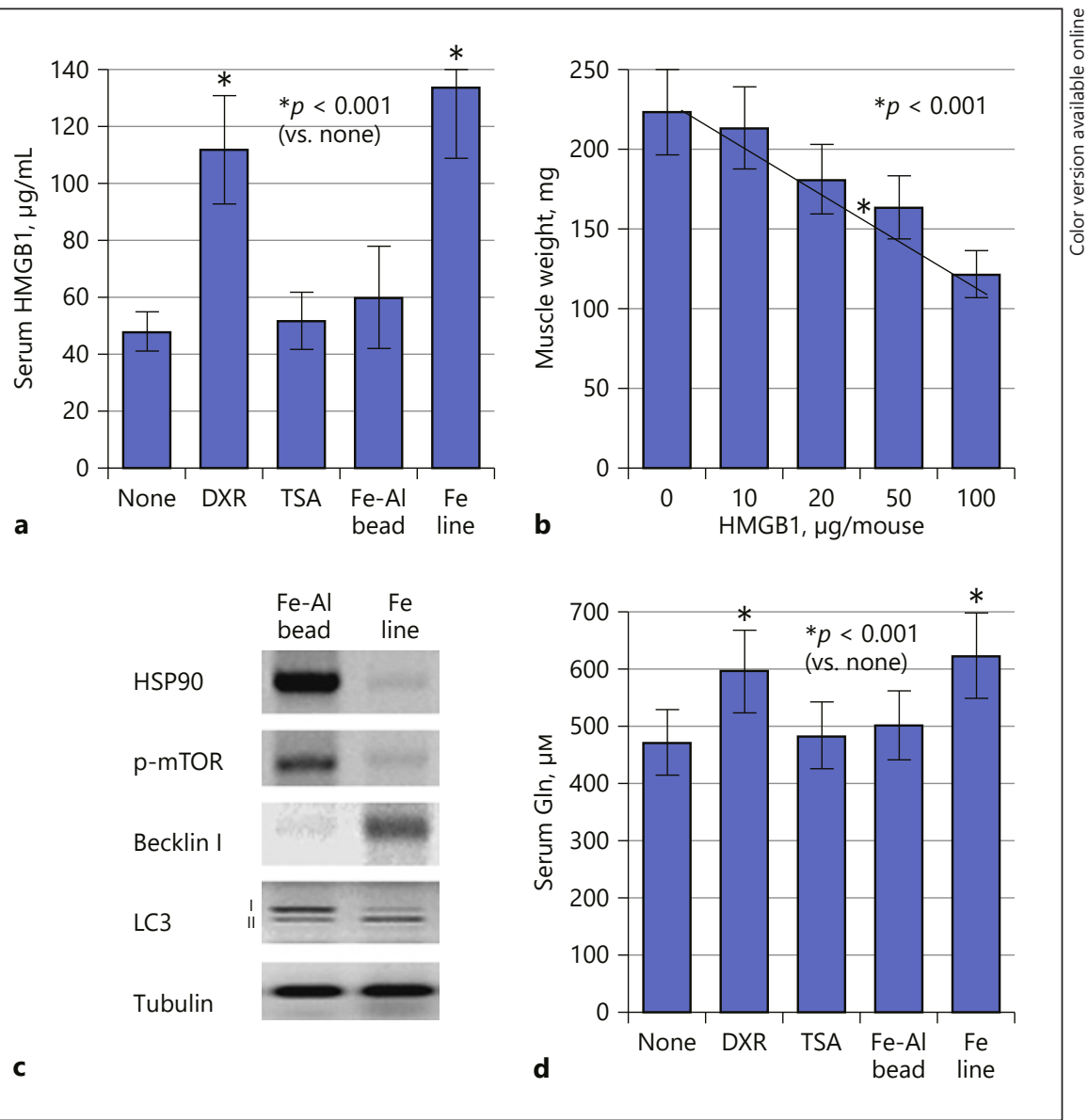

stimulated by HMGB1 was examined in the muscle heated by the alloy or Fe line (Fig. 4c). Heating by Fe lineinduced mTOR dephosphorylation and the subsequent increase of Beclin I and LC3 II, whereas heating by the alloy-induced HSP90 expression, preserved mTOR phosphorylation, and did not increase Beclin I or LCII. As a result of muscle autophagy, serum glutamine levels were increased in only DXR-treated and Fe line-heated mice (Fig. 4d).

\section{Discussion}

We have previously reported that HMGB1 released from cancer cells induces autophagy in skeletal muscle and subsequent cancer sarcopenia [5]. Cancer sarcopenia is also evoked by HMGB1 derived from necrotic cancer cells associated with anticancer chemotherapy [7]. To avoid chemotherapy-associated sarcopenia, it is important to establish non-necrotic cell death treatment for cancer. Therefore, in this study, we evaluated MHT using self-controlled heating elements consisting of Fe-Al milling alloy to confirm the apoptosis-based anticancer effect.

HMGB1 activates the receptor, receptors for advanced glycation end products, to inactivate mTOR, which induces autophagy in skeletal muscle [5]. Muscle autophagy results in free glutamine in the blood [5]. We observed that high temperature hyperthermia using Fe line resulted in cancer cell necrosis, which was associated with high serum levels of HMGB1 and glutamine and elevated autophagyrelated proteins. In contrast, hyperthermia at $43^{\circ} \mathrm{C}$ using $\mathrm{Fe}-\mathrm{Al}$ milling alloy yielded cancer cell apoptosis [16]. The apoptosis was associated with low serum HMGB1 levels, no induction of autophagy, and release of free glutamine. Hyperthermia at $43^{\circ} \mathrm{C}$ induced apoptosis, whereas high temperature hyperthermia-induced necrosis and release of HMGB1 in the blood. These results indicate that temperature is key in the prevention of sarcopenia.

In the present study, we distinguished TSA as an apoptosis inducer from DXR as a necrosis inducer. We have reported necrosis by DXR [7] and apoptosis by TSA [17]. We have examined cell death effect of anticancer drugs in 
other syngeneic tumor models, such as 5-fluorouracil and LL2 mouse lung cancer cell line in C57black6 mouse and docetaxel and 4T1 mouse triple-negative breast cancer in $\mathrm{BALB} / \mathrm{c}$ mouse. In these models, 5-fluorouracil- or docetaxel-induced necrosis mainly produced HMGB1 (data not shown). TSA induces apoptosis via nuclear factor $\kappa \mathrm{B}$ and $\mathrm{p} 53$ signal pathways $[18,19]$. HMGB1 released by cell necrosis induces cancer cell survival and regrowth of remnant cancer cells. Various anticancer drugs induce necrosis in cancer cells. In contrast, histone deacetylase (HDAC) inhibitors, such as TSA, induce apoptosis in cancer cells, which reduces the release of HMGB1. Then HDAC inhibitors are expected to avoid cancer cell regrowth. Moreover, our data in the present and previous studies suggest that suppression of HMGB1 release reduces skeletal muscle atrophy associated with cancer and the chemotherapy [5, 7]. HDAC inhibitors are focused for epigenetic targeting of cancer [20]. Our data suggest advantages of HDAC inhibitors for cancer treatment.

Recent studies have suggested a critical role of cancer stem cells in cancer progression, metastasis, and chemoresistance [21], thus necessitating novel cancer treatments to target cancer stem cells. Our data showed the reduction in cancer stemness was more pronounced by MHT at $43^{\circ} \mathrm{C}$ than by high-temperature hyperthermia, suggesting that $\mathrm{MHT}$ at $43^{\circ} \mathrm{C}$ is highly selective for cancer stem cells. Gao et al. [22] reported that in vitro hyperthermia at $40^{\circ} \mathrm{C}$ reduces side population and CD133-positive cells of the HCT116 and SW620 human colorectal cancer cell lines. Application of a magnetic field to heating is thought to increase the inhibitory effect [8]. Concurrent treatment of MHT with other anticancer treatments such as chemotherapy might cause a synergic effect, and this effect needs to be examined in the future.

In the present study, we used a milling alloy for heating elements. The milling alloy has high magnetic hysteresis and coercivity, which enables higher heating capacity in smaller volume [10]. Milling alloy of magnetothermogenic iron and nonmagnetothermogenic aluminum could provide a heating limit, enabling temperature selfcontrolled heating elements. The Fe-Al alloy bead facili- tated heating that was stable at $43^{\circ} \mathrm{C}$ in the subcutaneous tumor by alternating current at $700 \mathrm{~W}$.

Application of self-controlled heating elements has immensely contributed to cancer therapy with apoptosisinducing MHT [23]. In this system, heat limitation assures safety from overheating without heavy equipment to control power output and may eventually contribute to lowering the price of the method.

Multiple heating elements might be needed to be inserted into tumors of larger size for effective treatment. We are now developing needle-type heating elements to improve insertion in tumor regions. The powder of milling alloy is designed to be capsized by a needle-shaped titanium sheath [10]. It is planned not to remove beads remaining in the scarred tissue due to heat. The titanium sheath might be useful to reduce adverse events associated with remaining beads. To increase the practicality of the system, the magnetic interference could be considered and focused on.

In conclusion, MHT using Fe-Al milling alloy is a promising method for local treatment of cancer by targeting of cancer stem cells, induction of apoptosis, and avoidance of sarcopenia $[8,24]$. Further examination of this technique is required to determine its applicability in clinical use.

\section{Acknowledgment}

The authors thank Ms. Tomomi Masutani for expert assistance with the preparation of this manuscript.

\section{Discolsure Statement}

There are no conflicts of interests or financial ties to disclose from any authors.

\section{Funding Sources}

This work was supported by MEXT KAKENHI grant number 16H05164(H.K.), 17K15648(R.F.-T.), 17K19923(H.K.), 18 K17726 (I.K.).

\section{References}

1 Acharyya S, Butchbach ME, Sahenk Z, Wang $\mathrm{H}$, Saji M, Carathers M, et al. Dystrophin glycoprotein complex dysfunction: a regulatory link between muscular dystrophy and cancer cachexia. Cancer Cell. 2005 Nov;8(5):421-32.

MHT Using Self-Controlled Heating Elements in Cancer
2 Fearon K, Arends J, Baracos V. Understanding the mechanisms and treatment options in cancer cachexia. Nat Rev Clin Oncol. 2013 Feb;10(2):90-9.

3 Fearon KC. Cancer cachexia: developing multimodal therapy for a multidimensional problem. Eur J Cancer. 2008 May;44(8):1124-32.
4 Shachar SS, Williams GR, Muss HB, Nishijima TF. Prognostic value of sarcopenia in adults with solid tumours: A meta-analysis and systematic review. Eur J Cancer. 2016 Apr;57:58-67. 
5 Luo Y, Yoneda J, Ohmori H, Sasaki T, Shimbo $\mathrm{K}$, Eto S, et al. Cancer usurps skeletal muscle as an energy repository. Cancer Res. 2014 Jan; 74(1):330-40

6 Scaffidi P, Misteli T, Bianchi ME. Release of chromatin protein HMGB1 by necrotic cells triggers inflammation. Nature. 2002 Jul; 418(6894):191-5.

7 Luo Y, Chihara Y, Fujimoto K, Sasahira T, Kuwada M, Fujiwara R, et al. High mobility group box 1 released from necrotic cells enhances regrowth and metastasis of cancer cells that have survived chemotherapy. Eur J Cancer. 2013 Feb;49(3):741-51.

8 DeNardo GL, DeNardo SJ. Update: turning the heat on cancer. Cancer Biother Radiopharm. 2008 Dec;23(6):671-80.

9 Zhang Y, Calderwood SK. Autophagy, protein aggregation and hyperthermia: a minireview. Int J Hyperthermia. 2011;27(5):40914.

10 Taniguchi Y, Kodama K, Ichise T, Miki Y, Fukugauchi M, Asano M, et al. Capsulation process of fe powder particles by indent-extrusion of a multi-layered blank for hyperthermia cancer care: 9th ICOMM. Singapore: KUIS; 2014. p. 91.

11 Kodama K, Ichise T, Taniguchi Y, Miki Y, Fukugauchi M, Asano M, et al. Magnetocaloric property of mechanically fabricated needle shaped ferromagnetic implants for magnetic hyperthermia therapy. Sendai: The 53rd Annual Conference of Japanese Society for Medical and Biological Engineering; 2014.
12 Kodama K, Hirai K, Ichise T, Taniguchi Y, Yoshida A, Hosoito N, et al. Fabrication process and magnetocaloric property of aluminum based beads dispersed ferromagnetic particles for magnetic hyperthermia cancer care. Phuket: The 4th TSME International Conference on Mechanical Engineering. Phuket; 2013.

13 Kuniyasu H. The molecular pathology of gastric cancer. In: Kuriyama S, Yoshiji H, editors. New perspectives in cancer research and therapy 2005. Kerala: Research Signpost; 2005. pp. 85-98.

14 Chihara Y, Fujimoto K, Kondo H, Moriwaka Y, Sasahira T, Hirao Y, et al. Anti-tumor effects of liposome-encapsulated titanium dioxide in nude mice. Pathobiology. 2007;74(6): 353-8.

15 Kuniyasu H, Oue N, Wakikawa A, Shigeishi H, Matsutani N, Kuraoka K, et al. Expression of receptors for advanced glycation endproducts (RAGE) is closely associated with the invasive and metastatic activity of gastric cancer. J Pathol. 2002 Feb;196(2):163-70.

16 Ahmed K, Zaidi SF. Treating cancer with heat: hyperthermia as promising strategy to enhance apoptosis. J Pak Med Assoc. 2013 Apr;63(4):504-8.

17 Suzuki T, Yokozaki H, Kuniyasu H, Hayashi K, Naka K, Ono S, et al. Effect of trichostatin A on cell growth and expression of cell cycleand apoptosis-related molecules in human gastric and oral carcinoma cell lines. Int $J$ Cancer. 2000 Dec;88(6):992-7.
18 Hsu YF, Sheu JR, Hsiao G, Lin CH, Chang $\mathrm{TH}$, Chiu PT, et al. p53 in trichostatin A induced C6 glioma cell death. Biochim Biophys Acta. 2011 May;1810(5):504-13.

19 Yao J, Duan L, Fan M, Wu X. NF-kappaB signaling pathway is involved in growth inhibition, G2/M arrest and apoptosis induced by Trichostatin A in human tongue carcinoma cells. Pharmacol Res. 2006 Dec; 54(6):406-13.

20 Bai Y, Ahmad D, Wang T, Cui G, Li W. Research advances in the use of histone deacetylase inhibitors for epigenetic targeting of cancer. Curr Top Med Chem. 2019;19(12):9951004.

21 Vaiopoulos AG, Kostakis ID, Koutsilieris M, Papavassiliou AG. Colorectal cancer stem cells. Stem Cells. 2012 Mar;30(3):363-71.

22 Gao F, Ye Y, Zhang Y, Yang J. Water bath hyperthermia reduces stemness of colon cancer cells. Clin Biochem. 2013 Nov;46(16-17): 1747-50.

23 Gogoi M, Sarma HD, Bahadur D, Banerjee R. Biphasic magnetic nanoparticles-nanovesicle hybrids for chemotherapy and self-controlled hyperthermia. Nanomedicine (Lond). 2014 May;9(7):955-70.

24 Ahmed K, Tabuchi Y, Kondo T. Hyperthermia: an effective strategy to induce apoptosis in cancer cells. Apoptosis. 2015 Nov;20(11): $1411-9$. 